\title{
O Lazer Contemporâneo Ensaio de filosofia social
}

Resumo: Este livro revela as reflexões do autor sobre a evolução histórica do lazer e as características contemporâneas deste fenômeno que é visto de forma ampla e interligada com a cultura, a qualidade de vida, os serviços públicos e o consumo. Michel Bellefleur considera o lazer como um tempo-espaço em que são possíveis comportamentos baseados na liberdade de escolha. Para ele, o lazer está inscrito numa abordagem global da estruturação do conjunto do comportamento humano do qual ele é uma mediação dentre outras, uma mediação suscetível de contribuir para o desenvolvimento da vida pessoal e coletiva. $O$ lazer encontra facilmente seu lugar nas pulsões de vida polarizadas pela liberdade e o hedonismo utilizados com discernimento, inteligência e julgamento crítico. Ele se apresenta como um germe e um potencial de criatividade inserido num projeto de existência que cada um tem a responsabilidade de cultivar a sua maneira em função dos valores que dão sentido à vida, tanto individual quanto social.

Palavras-Chave: Lazer, Consumo, Qualidade de Vida.

Michel Bellefleur é filósofo e professor do Departamento das Ciências do Lazer e da Comunicação Social da Université du Québec à Trois-Rivières, no Canadá. Ele é autor, pela mesma editora, de L'evolution du loisir au Québec. Essai socio-historique (1997).

O objetivo deste ensaio é tornar público o resultado de uma reflexão amadurecida pelo autor ao longo dos últimos anos sobre o sentido do lazer contemporâneo e de sua presença cada vez mais estruturante da experiência da vida humana nas sociedades. Bellefleur esclarece que não segue uma escola de pensamento único

* BELLEFLEUR, Michel, Le loisir contemporain. Essai de philosophie sociale, Québec: Presses de l'Université du Québec, 2002. (Collection Temps Libre et Culture) (192 p.)

* * Pós-Doutoranda em Sociologia do Lazer junto ao Programa de Pós-Graduação em Ciências Sociais na Universidade Federal de São Carlos. Doutora em Ciências Sociais pela Universidade Estadual de Campinas.

Movimento, Porto Alegre, v. 10, n. 2, p.147-166, maio/agosto de 2004 
ou particular e que procura fazer uma abordagem eclética e transdisciplinar, uma vez que a realidade existencial do lazer transcende geralmente as contribuições disciplinares.

O estudo do lazer é o estudo de um fenômeno que tem a mesma idade que a humanidade. O lazer se inscreve numa franja de valores a partir do coeficiente de liberdade. "Ele [o lazer] se enraíza ontologicamente na porção do ser que tem a característica de poder se desobstruir relativamente do determinismo para inventar ou adotar modos de ser e de vida que estruturam projetos de existência, seja no conformismo, na criatividade ou, o que é o caso mais freqüente, numa mistura dos dois. Sobre este plano, ele constitui um quadro e uma ferramenta de cultura, no sentido antropológico clássico do termo, enquanto processo permanente de transformação do homem pelo homem, assim como de seu meio ambiente natural e social" (Bellefleur, 2002, p. 2).

Uma das teses do autor é que o lazer, de nenhuma maneira, pode ser apreendido adequadamente se ele é visto como um microcosmo fechado sobre ele mesmo, um "mini-mundo" autosuficiente em relação as suas realidades, suas formas e suas práticas particulares. Para Bellefleur, o lazer está inscrito numa abordagem global da estruturação do conjunto do comportamento humano do qual ele é uma mediação dentre outras, uma mediação suscetível de contribuir para o desenvolvimento da vida pessoal e coletiva.

Os termos lazer e otium sempre foram, na realidade, elementos de linguagem que evidenciam o lazer como multiforme, portanto, é um erro, segundo o autor, querer circunscrever para o lazer, com precisão, um universo situacional que não existe no vivido dos indivíduos ou das coletividades. O lazer sempre foi um privilégio nos modos de vida das classes superiores e sua democratização nas sociedades ditas avançadas contemporâneas representa apenas uma feliz ampliação de sua existência. Na época do Império Romano o conteúdo do possível [loisible] ${ }^{1}$ foi identificado com o vocábulo vago de otium. Este termo fazia parte da vida daqueles cidadãos que podiam gozar de privilégios. O trabalho de produção material era responsabilidade dos escravos, seres privados de todo direito e limitados à uma restrita condição de consumo de sobrevivência. Estas pessoas não tinham nenhum acesso ao otium. O otium significava repouso, relaxamento, descanso, diversão, o livre desenvolvimento dos gostos, talentos e atitudes, o que lembra a

1 Em francês, lazer é loisir e a palavra loisible, de mesma raiz, significa permitido, possível.

Movimento, Porto Alegre, v. 10, n. 2, p.147-166, maio/agosto de 2004 
célebre trilogia contemporânea das finalidades do lazer, de Dumazedier, dos 3D: descanso, divertimento e desenvolvimento. Os cidadãos romanos que não precisavam trabalhar no sentido de produzir bens à sua subsistência se dividiam entre o otium e o nec otium. Este último significava a falta de repouso e o conjunto das atividades obrigatórias que comportava sua posição social (cargos públicos, tarefas políticas, missões de guerra ou do comércio, etc). Nec otium é a origem dos termos negócio, negociar e negociação.

Segundo Bellefleur, a sociedade contemporânea não inventou novas formas de otium. Ela subsumiu o antigo, mas generalizando a obrigação de trabalhar para o alto da pirâmide social ampliando a cidadania para a base, o que constitui uma marca de civilização. É difícil, diz o autor, querer dar a todos o que foi reservado historicamente a punhados ínfimos de privilegiados durante milênios. O hedonismo, segundo o autor, pode ser visto como uma dimensão geral de uma experiência vivida de lazer. O lazer, como o ócio clássico, se refere à uma estrutura comportamental de base que se manifesta seja na repetição de gestos costumeiros, o que é o caso na massa dos indivíduos, seja na busca e experimentação do inédito.

A hipótese que o autor defende no primeiro capítulo de seu livro é a de que o hedonismo associado ao lazer deve conservar uma dimensão relativamente arbitrária sob pena de alienação da liberdade de escolha. Este lazer deve conservar uma orientação inalienável em direção das iniciativas autodeterminadas emanantes da pulsão de vida e do princípio de prazer. O autor chama a atenção para outros fatores que afetam diretamente a liberdade e o hedonismo e lembra Marcuse para mostrar que o processo de sedução consiste em propor uma relação de causalidade entre o uso de certos bens e serviços e a atualização do princípio de prazer. O indivíduo é submetido permanentemente à sedução do "sistema de objetos" (Baudrillard) inundado pelos interesses do mercado. A situação ideal desejada seria um estado de osmose entre os comportamentos do consumidor e os interesses do mercado. Uma situação normal poderia ser formulada assim: a sedução propõe, a liberdade dispõe segundo a capacidade de discernimento do indivíduo. Na sociedade de consumo - que o autor analisa um pouco mais criticamente no primeiro capítulo do livro mas cuja crítica parece abandonar nos capítulos seguintes - o hedonismo se torna uma ética popular por sua utilidade sistêmica, pelo enquadramento planificado dos prazeres da existência, os quais são simultaneamente propostos à iniciativa ou ao conformismo do 
indivíduo-cidadão e definidos como via normal de sua integração ao corpo social.

A existência do tempo livre não está isento de efeitos perversos se este tempo livre não for associado a outras dimensões facilitadoras, como a distribuição igualitária da riqueza, a elevação do nível da educação e da saúde. "O tempo livre não tem grande significação quando ele é vivido na anomia, indigência e pobreza, carência educativa e a retração social forçada. Ele manifesta então, mais a vacuidade que a riqueza da existência e pode facilmente degenerar em patologias tanto individuais quanto sociais.[...] O lazer pressupõe um espaço-temporalidade liberado que não esgota sua significação, mas constitui seu trampolim, o pré-requisito ou a condição situacional. Ele só se torna lazer quando abre a via aos comportamentos escolhidos e autogeridos suscetíveis de ocupá-lo e de lhe dar sentido. Ele é sempre vivido como um processo de hedonização do tempo" (Ibid,. p.19). Mas este processo é híbrido, polivalente e multidirecional. Mesmo se um grande número de práticas de lazer podem parecer relativamente estáveis, elas se inscrevem no campo da temporalidade humana onde tudo muda: os contextos, os valores, os afetos, os modos etc. O círculo de possibilidades oferecido às pessoas, aos grupos e às classes sociais é flutuante segundo a idade, o sexo, o nível de vida, a educação e o desenvolvimento cultural.

O tempo livre ou liberado é uma condição necessária ao lazer, mas insuficiente. A simples observação social mostra a existência de indivíduos e de grupos dispondo de tempo dito livre e se mostrando impotentes para se dar uma vida de lazer por falta de meios para preenchê-lo. Em última instância, o lazer tem chances de existir de maneira diretamente proporcional ao estado de realização concreta do conjunto dos direitos e liberdades da pessoa. Mas, um lazer acessível e democrático é incompatível com uma sociedade opulenta que tolera a pobreza e a indigência.

Bellefleur afirma que a melhor garantia de sobrevivência da sociedade neoliberal reside na promoção do hedonismo generalizado. O consumidor pode ser mais que um átomo ou menos vitimado pelo sistema o qual o deixa a possibilidade de reagir, em virtude dos mesmos direitos de liberdade que ele promove, participando de movimentos sociais, culturais e políticos inovadores e críticos. No entanto, salienta o autor, uma reação de autonomia plena à estas incitações manipuladoras é muito difícil. "Poucos indivíduos dispõem do capital de autonomia e de afirmação de si 
para reagir contra isto com uma forte dose de atitudes críticas e seletivas. A sedução está em condições relativamente favoráveis. [...] A maioria dos cidadãos-consumidores adormece e se molda facilmente numa aceitação tácita da manipulação da qual ela é ao mesmo tempo vítima e beneficiária, numa espécie de alienação confortável, aberta às solicitações do mercado, por mais fugitivas que elas sejam" (Ibid, p. 26-7).

O lazer, seja em qualquer uma das suas versões - lúdico, festivo, esportivo, artístico, turístico, social ou cultural - se apresenta como uma vasta operação de mercantilização do hedonismo, do mais trivial ao mais refinado. Sua configuração é a mesma de um mosaico, híbrido e aberto, alimentada por uma minoria de promotores e de criadores. "Em geral, ele é um reflexo fiel das relações sociais principais presentes na sociedade" (Ibid., p.28). O lazer nunca é um refúgio idílico da individualidade cortada da realidade social e se afirmando por ela mesma. Na realidade, ele é apenas uma instância da vida particular onde se repercutem as mesmas tensões e conflitos que agitam a sociedade global.

A liberdade e o prazer, no lazer e em outros setores do consumo, não são deixados abandonados à iniciativa descontrolada dos indivíduos e dos grupos; existem forças de manipulação que os domesticam pela sedução e a convicção. Neste sentido, numerosas práticas de lazer são menos ações verdadeiramente livres e hedonistas e mais funções normalizadas se inscrevendo num processo de exploração alargada. Lembrando Marcuse, o autor afirma que as técnicas de manipulação das massas desenvolveram uma indústria dos lazeres que controla diretamente o tempo de lazer. Os lazeres, no plural, são vistos como produtos para colocar no mercado e a serem explorados de maneira rentável.

A exploração da abundância das sociedades de consumo dão ar mais humano ao capitalismo e o lazer acaba por se tornar um lugar chave do boom do mercado que define e promove de maneira interessada um disfarce ilimitado dos usos da abundância. O lazer assim proposto torna-se um instrumento de sedução da liberdade e do hedonismo. "O lazer se tornou mais ou menos deliberadamente o desejo de felicidade próprio ao instinto de vida de cada indivíduo colocado ao serviço dos interesses do sistema capitalista que tem necessidade das necessidades de cada consumidor (o exército de reserva das necessidades" de J. Baudrillard)" (Ibid., p.32). O indivíduo, que não pode viver sem consumir, está forçosamente num estado de "consciência sob influência". O conjunto dos lazeres

Movimento, Porto Alegre, v. 10, n. 2, p.147-166, maio/agosto de 2004 
oferecidos constitui um supermercado orientado para o consumo e a cultura de massa onde os promotores brigam pelo tempo, dinheiro, o desejo e a alegria dos cidadãos. O mercado não tem, evidentemente, interesse em que o mesmo cidadão invente ou produza os bens ou objetos necessários para o seu lazer. Bellefleur lembra bem: quanto mais abundam os objetos fabricados industrialmente, menos criatividade os cidadãos terão.

Mencionando princípios da fenomenologia, o autor afirma que "O que caracteriza o lazer [...] é que ele é portador de uma intencionalidade liberada da necessidade e, por este fato, orientado para objetos multiformes e polivalentes, em número indefinido e comportando, cada um deles, suas pressões face às quais o indivíduo-cidadão deve ter um julgamento preferencial e tomar uma decisão determinada do interior ou do exterior" (Ibid, p.334). O lazer não dispõe de uma axiologia que lhe seja própria ou exclusiva; todos os valores humanos, individuais ou sociais, podem nele repercutir ou encontrar eco. Suas formas de existência são históricas e se inscrevem no movimento flutuante e na relatividade. Entretanto, isso não reduz em nada sua importância na existência individual e a vida social.

Definir o lazer, diz Bellefleur, consiste menos em lhe dar um conteúdo que de compreendê-lo como processo comportamental enraizado na pulsão de vida que busca se realizar, enquanto ela dure, numa maneira inicialmente poliforme e polivalente. O que caracteriza sua versão contemporânea é que ele é agora vivido numa sociedade de direito democrática e de cidadania alargada, o que o distingue de todas as formas antigas de otium. O autor reforça sua idéia de que não é interessante buscar uma definição precisa para o termo lazer, pois seria muito difícil que um conceito desse conta da relatividade existencial do lazer. Mas, salienta que a única constante universal do lazer é que ele se apresenta como um ato escolhido ligado à uma pulsão de vida percebida como positiva.

Tanto licere quanto culturare, em latim, são verbos e não substantivos, por isso, o autor prefere tratar o termo lazer como um "conceito virtual", concebendo a virtualização como um vetor de criação de realidade. O lazer seria um termo da língua vindo da dialética do virtual e do atual. "[...] como uma mesma prática de lazer pode também estar associada a múltiplas pretensões intencionais paralelas ou combinadas, até mesmo opostas e contraditórias, em matéria dos valores e dos interesses humanos, é talvez preferível não pré-estabelecer nada a seu respeito" (ibid.,

Movimento, Porto Alegre, v. 10, n. 2, p.147-166, maio/agosto de 2004 
p.41). Assim, o autor fala de uma "conceitualização relativa do lazer", uma vez que o lazer e a cultura comportam aspectos subjetivos, idiossincráticos, de forma que as pulsões afetivas superam ou são determinantes sobre as opções morais e orientações sociais.

As formas gerais do lazer são apresentadas pelo autor numa tabela que compreende o seguinte: 1 . O lazer humanista - centrado na afirmação dos direitos humanos; 2 . O lazer educativo - orientado para a aprendizagem das práticas do lazer; 3. O lazer moral centrado na utilização das formas de lazer permitindo a regulação dos comportamentos segundo as normas socialmente reconhecidas; 4. O lazer religioso - associado à seleção e à prática de lazeres relacionados com alguma doutrina; 5 . O lazer cultural - definido assim por sua capacidade para operacionalizar processos de enculturação e de aculturação e promover as dimensões estéticas da vida humana; 6. O lazer terapêutico - associado às práticas curativas de saúde mental ou física; 7. O lazer político - ligado às ações preconizadas por um partido político ou um governo portador de um projeto de sociedade; 7. O lazer ambientalista - definido em relação com as preocupações de natureza ecológica para melhor qualidade de vida das pessoas e, 8 . O lazer mercadológico - centrado na exploração lucrativa e rentável do consumo que propõe valores apresentados como portadores de hedonismo ou de felicidade.

Concluindo o segundo capítulo, o autor ressalta que o tempo livre não tem apenas atributos positivos de descanso, felicidade, recuperação. Ele também pode instalar o tédio, o medo, a solidão não desejada, a anomia. Em si mesmo, ele é apenas um vácuo portador de virtualidades multidirecionais. Esta é o que o autor chama de "a face escondida do lazer". Traduzida em termos freudianos, esta expressão significa que o lazer pode corresponder tanto às pulsões de vida quanto às pulsões de morte. Lembrando que o lazer tem também formas negativas de existir, o autor afirma que "Na realidade, a complexidade das interações múltiplas entre os impulsos emocionais, os níveis de lucidez da consciência e as capacidades (ou incapacidades) de julgamento é tanta que tudo é possível. O lazer tem também suas mortes, seus suicídios, seus mutilados e, de um modo geral, sua morbidade tanto física como mental" (Ibid. p.81). As abordagens negativas do lazer podem ser apenas acidentais, mas fazem parte da estrutura do comportamento humano, o que, por si, já se choca com a abordagem conceitual que trata apenas dos aspectos positivos do lazer como se fossem únicos.

Movimento, Porto Alegre, v. 10, n. 2, p.147-166, maio/agosto de 2004 
No terceiro capítulo, o autor se propõe a analisar a cultura. Em função das mudanças tecnológicas e em todas as direções na história, lazer e cultura se tornam cada vez mais zonas ou campos de existência abertos à pluralidade dos possíveis. O lazer contemporâneo, segundo Bellefleur, tornou-se muito mais que um instrumento de descanso, de recuperação ou de evasão das diversas formas das vicissitudes ou da alienação do trabalho. A cultura continua exprimindo o conjunto das transformações realizadas pelo homem sobre seu universo material ou ideal. Nesse sentido, ela não é mais propriedade exclusiva de criadores socialmente reconhecidos como tais (artistas, por exemplo). A cultura se dirige democraticamente a cada pessoa segundo sua capacidade de arrumar seu modo de vida e de elaborar seus projetos de existência. O lazer ultrapassa o universo dos jogos, dos esportes e dos divertimentos e a idéia de cultura se encontra reduzida quando pensada somente no mundo das artes.

Segundo o autor, a criatividade é o que mais se partilha no mundo, pois é latente em todos os seres humanos e se exprime conforme o potencial de cada um, o qual, por sua vez, é variável ao infinito, mesmo que comporte limites. O lazer fornece à criatividade um contexto virtual às múltiplas formas caracterizada pelo hedonismo autogerido de acordo com o círculo de possibilidades de cada um, o qual leva em conta gostos e aspirações, talentos, pressões e limitações diversas, nível de liberdade e de autonomia de comportamento, estado de educação e cultura, acesso ao capital cultural adquirido de seu meio (Bourdieu), inserção nas redes organizadas, etc. Como o lazer se tornou uma dimensão estruturante da vida cotidiana nas sociedades avançadas, não há mais porque tratá-lo como um epifenômeno ocasional, como uma festa, uma viagem, um espetáculo, por exemplo.

Etimologicamente, a cultura é da ordem do processo do fazer ou do agir. Ela tem uma extensão mais ampla que o lazer. Ela comporta um conjunto de realidades da vida humana. Ela toca o conjunto do ambiente natural e social criado, construído e administrado pela atividade humana consciente. "Ela comporta técnicas, processos de produção, das idéias, dos valores, dos usos e costumes, dos sabores, dos ritos e dos ritmos, das crenças e todo um conjunto de dados suscetíveis de serem comunicados, assimilados, assim como transformados" (p.91-2).

O autor diz que o lazer como prática cultural concreta se vive de uma maneira globalmente bipolar, sob forma de lazeres 
expressivos e impressivos, definidos da maneira seguinte: os lazeres expressivos são os que repousam sobre a implicação ativa da pessoa na realização concreta do objeto de seu lazer. Trata-se de uma participação - solitária ou coletiva - na produção do conteúdo de seu lazer. Os lazeres impressivos são os caracterizados menos pela implicação ativa e mais pela reação às produções de outros. A idéia de reação refere ao fato que o indivíduo-cidadão e consumidor não tenha sido o agente efetivo de sua realização; sua reação é da ordem da escolha e da discriminação e depois inclui o conjunto de seus comportamentos participativos à oferta social que lhe chega de múltiplos horizontes. Ele conserva a autonomia da escolha.

A capacidade dos indivíduos de satisfazerem suas necessidades reais ou induzidas corresponde, grosso modo, ao seu posicionamento nas classes sociais, ao seu nível de vida, de educação e de saúde, assim como ao seu acesso democrático à uma sociedade de serviços múltiplos (elementos de mobilidade social ascendente que amplia de fato o potencial dos indivíduos e dos grupos). A sorte de cada indivíduo pode ser melhorada pelo conjunto dos processos da ação coletiva. Numa sociedade aberta e democrática, dialeticamente, podem sempre nascer contra-modelos aspirando a tornarem-se dominantes (como a contra-cultura).

Bellefleur vê o lazer e a cultura de forma imbricada; tudo o que se aplica ao lazer se aplica a cultura, diz ele, com exceção do fato que o lazer não teria a pretensão de cobrir todo o campo da experiência e da existência humanas. "Quase todas as formas de práticas culturais têm sua versão associada ao lazer. [...] lazer e cultura coexistem em um casamento permanente e paralelo. A cultura é sempre a tela de fundo do conjunto das práticas de lazer, sua matriz e seu campo de evolução, seu ponto de partida e seu ponto de chegada" (Ibid., p.101). O lazer pressupõe diferentes formas de liberação. A idéia de cultura que cola à realidade do lazer é a que a reconhece como sendo fundamentalmente constituída de um "patrimônio vital" (sentido usado pela UNESCO) no qual cada indivíduo deve se inserir para o desenvolvimento de sua existência. O patrimônio visa englobar - enquanto base social de referência geral e de evolução - uma variedade de realidades: "um conjunto de regras e de normas regendo o curso da vida, das idéias e dos julgamentos, dos ritos, crenças e ideologias, das sensibilidades e dos afetos múltiplos, assim como dos modos de ser e de fazer que se encarnam em modos e estilos de vida plurais. O que nós chamamos comumente cultura é a totalização destes

Movimento, Porto Alegre, v. 10, n. 2, p.147-166, maio/agosto de 2004 
elementos; o que chamamos lazer concerne as escolhas comportamentais de caráter hedonista tiradas de um universo cultural acessível a cada um, seja de proximidade ou ligado na universalidade da espécie humana. (Ibid. p. 102).

A cultura permite a identidade na diferença, a idiossincrasia na interdependência. Ela deve se acomodar ou se adaptar às desigualdades individuais ou de classes sociais. Ela vive continuamente a tensão entre os interesses individuais e os coletivos. Ela visa uma certa coesão social que é sempre relativa e combina vários elementos antagônicos que são a base de sua mudança ou movimentos perpétuos. "[...] a cultura é a fonte do sistema das orientações escolhidas em uma sociedade por aqueles que exercem o poder, mas ela sofre também seus efeitos. Ela é retocada, remodelada ou transformada pelo jogo dos atores sociais que se referem nela ou lhe são exógenas. Ela evolui e se vê constantemente modificada pelos múltiplos fatores (econômicos, políticos, espirituais, simbólicos, etc.) relevando tanto da conjuntura quanto das estruturas sociais" (Ibid. p. 103).

Bellefleur lembra que a cultura tem uma dimensão original de processos polivalente de desenvolvimento das coisas e do espírito humanos. Este processo comporta dois lados complementares e sinergéticos: enculturação e aculturação. Enculturação é a inserção do indivíduo e de suas características próprias, sua contribuição particular - por mais modesta que ela seja - para a realização de um patrimônio coletivo em evolução. A enculturação é o processo de interiorização dos códigos e discursos presentes em toda cultura que enquadram as percepções da consciência do senso comum e regem a fixação das orientações vitais, validando-os na relatividade dos seres e das coisas, remete à idéia de cultura endógena como desenvolvimento de si próprio que torna o indivíduo mais hábil e apto para participar da produção cultural comum e coletiva.

Segundo este autor, o lazer é cada vez mais um vetor privilegiado da enculturação, pois possibilita comportamentos reais e virtuais baseados na liberdade de escolha e no hedonismo e que não pára de se expandir em quantidade e qualidade. Todas as formas de lazer, segundo este autor, estão centradas na busca da felicidade humana com os meios mais idôneos. A sociedade de consumo incluindo a mercantilização dos objetos ditos de cultura - é uma gigantesca empresa de enculturação orientada por objetivos e interesses que não são próprios das pessoas e que as manipulam pela sedução (Baudrillard). Mas, Bellefleur acredita que a sedução 
desta sociedade não chega à coação de comportamentos, uma vez que a lucidez das pessoas e sua capacidade de julgamento não são tão afetadas assim, sobretudo quando se leva em consideração as múltiplas possibilidades que se oferecem aos indivíduos. O autor vê a enculturação e o lazer como possibilidades de autogestão do consumo e da criatividade compreendidas como processos de desenvolvimento humano livremente escolhido. O lazer está sendo visto pelo autor como sinônimo de hedonismo associado à liberdade de ser e de fazer, de se exprimir e de criar, de permissividade social e de uso arbitrário dos recursos disponíveis.

A aculturação toma as formas de sociabilidade que acompanham e modelam a vida do homem, ou seja, compreende todos os elementos do "outro" no "eu" formando a identidade individual e coletiva de cada um. "A existência humana se realiza simultaneamente para si, por e com o outro, e as vezes contra ele" (Ibid., p.113). Durante toda a sua vida o indivíduo está em situação potencial de aculturação permanente. O lazer é a porção arbitrária da aculturação, é o vivido escolhido de cada um. A idéia mesma de lazer implica que ele pode e deve aceitar ou recusar as incitações ou os convites que implicam uma certa influência exclusiva sobre seu tempo, suas capacidades e seus recursos arbitrários. A aculturação é um processo de desenvolvimento cultural lento e incerto quanto aos seus resultados. É um negócio a longo prazo que funciona melhor com a familiarização. O indivíduo se sente mais disposto a participar ativamente à porção da cultura geral com a qual ele se sente em estado de afinidade de gosto e de interesse. A absorção (aculturação) implica uma tomada de consciência reativa depois da recepção ou impressão sensorial.

O que importa no lazer, diz Bellefleur, é menos a diversidade de suas formas que o fato que seu conjunto constitui uma imensa feira de valores humanos desejados, esperados. Mesmo as formas mais simples de lazer podem ser acopladas à busca de valores maiores cuja importância não salta aos olhos de uma observação superficial ou unicamente quantitativa. O lazer permite a simbiose entre enculturação e aculturação no seio de um mesmo projeto de existência. Ele se inscreve no desenvolvimento cultural e, por isso, é inevitável, segundo o autor, que o lazer se torne uma questão sociopolítica que implica uma ligação com a cultura.

No quarto e último capítulo, o autor defende a tese de que a sociabilidade é uma dimensão estruturante da condição humana e

Movimento, Porto Alegre, v. 10, n. 2, p.147-166, maio/agosto de 2004 
de que a sociedade é também o resultado da ação dos sujeitos humanos que a compõem, a transformam e a reinventam sem cessar. Bellefleur ainda trata do lazer privado e público. As sociedades liberais e democráticas, aliadas ao avanço tecnológico e científico, criou as condições históricas da valorização da vida privada gerando enriquecimento e individualismo ao domínio privado. Uma grande parte dos lazeres hoje democraticamente acessíveis foi anteriormente experimentada sob forma de lazeres de classes privilegiadas. Estas classes levavam vantagens tanto no plano a vida privada quanto no plano da vida pública. De forma inversa, a incapacidade ou impotência pública se refletia fielmente nas carências da vida privada. Os grupos sociais desfavorecidos sofrem de uma precariedade na sua vida privada tanto quanto da ausência de participação social.

A vida privada é não somente o refúgio da intimidade mas também a incubadora da vida social. Ela é ao mesmo tempo o laço de afirmação e de consolidação do eu. O laço social tem a especificidade de ter um caráter instrumental necessário para a vida social dos indivíduos. Numa sociedade democrática, diz Bellefleur, o indivíduo goza de uma margem de manobra lhe permitindo comportamentos escolhidos. Esta margem se refere também ao fato que muitos atores sociais no seio da sociedade de abundância têm um interesse quase vital em amplificar o consumo sem poder restringi-lo. Segundo o autor, além das forças consideráveis da manipulação e da sedução, se desenha para cada indivíduo um horizonte de possibilidades cada vez maior de praticar comportamentos definidos em adequação com seus traços distintivos, contanto que ele não ultrapasse as pressões e restrições próprias de seu meio social.

O autor justifica que prefere manter distância das abordagens críticas sobre consumo e lazer para poder afirmar que o crescimento do acesso ao consumo e ao lazer constitui um fermento de crescimento econômico e cultural na coletividade. Segundo Bellefleur, a influência sobre a consciência dos indivíduos é tão antiga quanto a humanidade e o crescimento do consumo de massa manipulada é apenas um acontecimento a mais, maléfico ou benéfico segundo os diferentes pontos de vista e os interesses.

Adotando uma perspectiva mais romântica e utilitarista, o autor afirma que o lazer pode visar e valorizar a liberação de uma vida social restrita e insuportável. É um momento de se debruçar sobre si e sobre escolhas e projetos pessoais, o que não significa 
uma extração pura e simples do social. "[...] em situação humana normal, quer dizer não alienada, o lazer se apresenta como um fator de crescimento do potencial do laço social sob todas as suas formas imagináveis e voluntariamente escolhidas, tanto na vida privada quanto na vida pública. [..] O lazer acomoda bem relações humanas intersubjetivas, amorosas, amigáveis, de afinidades, centradas na cooperação ou competição, na sociabilidade formal ou informal, na inserção nas redes de interesses múltiplos, na participação molecular em públicos ou multidões, na freqüência a lugares e espaços permitindo a descoberta, no contato com o Outro, na criação individual ou coletiva, na implicação nos grupos ou organizações de participação voluntária e benévola, por atração ideológica ou em vista de ações sociais particulares, e assim por diante. O lazer dilata o laço social possível de uma maneira diretamente proporcional a seu espectro de formas de existência. De uma maneira geral, a seleção de práticas de lazer, ou sua rejeição, está estreitamente associada ao laço social desejado ou detestado pela pessoa implicada na prática, o espírito de competição por exemplo" (Ibid., p.133).

Segundo Bellefleur, não se pode reduzir o indivíduo ao estado de consumidor seduzido, manipulado ou alienado de toda autonomia comportamental. A alienação é, assim como a liberdade, um negócio de coeficiente. Se a alienação fosse total (perda de sentido e de direção dos comportamentos) tudo o que se diz sobre o lazer não teria sentido e este livro não teria razão de ser: o lazer seria apenas um efeito de controle social extra-determinado. Toda dominação tem suas falhas e interstícios. O lazer representa o tipo de situação comportamental em que o outro pode ser selecionado livremente em relação com afinidades eletivas, sem necessariamente compartilhar o conjunto de seus projetos de existência. O fenômeno associativo do lazer é um traço dominante de sua presença na sociedade civil. “Ele é antes de tudo a expressão de uma consolidação da sociabilidade escolhida com base na intersubjetividade" (Ibid., p.140).

Ao tratar de política pública de lazer, o autor salienta que o lazer deve se inserir nas questões sociais "sérias", ao lado da educação, da saúde, do meio ambiente, da segurança, etc. É um direito humano reconhecido há mais de meio século. Mas, contraditoriamente com o que apontou páginas antes, o autor pondera que o lazer "não foi nunca e jamais será um 'nirvana' que liberta momentaneamente das duras realidades ou pressões sociais

Movimento, Porto Alegre, v. 10, n. 2, p.147-166, maio/agosto de 2004 
fornecendo uma parcela de paraíso terrestre num espaço-tempo dito livre. Esta visão das coisas, sem ser completamente falsa, é ao menos parcial. A realidade do lazer é menos idílica ou virginal" (Ibid. p. 144). O lazer não é um estado gratificante em si, mas um instrumento ao serviço das mesmas finalidades que o indivíduo persegue. Ele é motivado por atitudes de fuga, de ruptura ou de evasão.

O lazer tem sido invadido por grupos de interesses baseados no comércio e no consumo, reduzindo o indivíduo-consumidor ao "utilizador pagante". Estes grupos tendem a cobrir os jogos e esportes, os espaços privados de sociabilidade, o turismo, as artes, as letras, os lugares naturais de alegria da vida, os espetáculos, etc. Estes grupos utilizam capital público para fins privados ou busca de lucro, como a prática de mecenato, por exemplo. Estes grupos têm o estatuto de organização sem fins lucrativos e estão subordinados aos interesses particulares de cada um de seus componentes visando a sua promoção. É o caso de organizações profissionais e sindicais, redes de serviços com promoções esportivas, festivas, artísticas e outras. Para Bellefleur, estes grupos produzem lazer e cultura de forma fragmentada e o principal denominador comum é a rentabilidade ao serviço do capital investido pelos seus promotores. "Um lazer inteiramente enquadrado e programado nos limites do mercado e prioritariamente centrado nas vontades dos grupos de interesses sofreria certamente uma redução de sentidos e uma perda de criatividade. Mas a sociedade civil não é apenas isso: ela dispõem também de um capital social e cultural com finalidades outras que não apenas monetárias" (Ibid., p.149).

A realidade do lazer contemporâneo está longe de se esgotar na única referência às relações de troca do tipo mercadológica em que sempre há custo e extração de mais-valia em benefício do capital. O lazer também engendra organizações sociais que perseguem todo tipo de objetivos e nem sempre de ordem financeira, organizações sem fim lucrativo. Estes são também iniciativas tomadas no seio da sociedade civil por indivíduos dinâmicos que querem estabelecer livremente relações com outros indivíduos em função de centros de interesses comuns. O lazer, pela multiplicidade de formas das práticas que o exprimem, é um terreno fértil para a criação e a operacionalização de tais organizações.

Uma boa parte da situação do lazer contemporâneo remete à ação histórica dos movimentos sociais, não somente pelos eu conteúdo, mas também por suas condições prévias. “[...] o lazer

Movimento, Porto Alegre, v. 10, n. 2, p.147-166, maio/agosto de 2004 
democrático moderno não nasceu da filantropia capitalista. Ele lhe foi, por assim dizer, arrancado por alta luta emergindo da miséria que ele criou ou manteve a seu favor" antes de tornar-se um lugar de exploração da abundância na sociedade de consumo de massa (p.153). Desde o fim do século XIX, o lazer vem evoluindo de causa em causa pelos movimentos sociais que passam de um objeto de reivindicação a outro, como as lutas pela redução da jornada de trabalho, pelas férias, pelos feriados remunerados, pela melhora das condições de vida no trabalho e fora dele. Mas, salienta o autor, seria exagero afirmar que o lazer seja o resultado direto e exclusivo da ação histórica dos movimentos sociais. O realista é afirmar que o lazer contemporâneo foi bastante favorecido pela efervescência da mudança social positiva e qualitativa animada pelos movimentos sociais.

Ao tratar de lazer, política e Estado, ao final de seu livro, Bellefleur afirma que o Estado deve levar em consideração realidades humanas fundamentais baseadas em outros critérios que não apenas o da rentabilidade monetária e das leis de mercado. O sentido mais positivo e mais nobre do termo "serviço público" está ligado à "idéia de justiça social distributiva". "A idéia de justiça social se refere fundamentalmente ao fato de que cada cidadão dispõe de uma infra-estrutura de bens e serviços coletivos à qual ele tem acesso para fundar e realizar seus projetos de existência" (p.161). A mercantilização generalizada e rentável para o capital introduz a segregação e a desigualdade no acesso à infra-estrutura mínima necessária ao desenvolvimento humano normal. "Mas, qualquer que seja, toda sociedade [...] terá sempre a necessidade de se dotar de uma superestrutura de poderes públicos capazes de desenvolver a multiplicidade de serviços essenciais para a realização de uma cidadania integral, o que, bem entendido, pode variar consideravelmente no tempo e no espaço, assim como de um grupo humano a outro. Assim, o papel do Estado encontra sua especificidade no governança do dinamismo da sociedade civil para o bem comum e no que completa sua própria ação no mesmo sentido" (p.162).

Importante frisar, como o faz Bellefleur, que "os papéis e funções do Estado diante do lazer não são radicalmente diferentes dos que ele tem por exemplo em matéria de educação, de saúde, de segurança e de meio ambiente, para pegar apenas questões sociais que lhe são estreitamente aparentadas" (p.162). O Estado tem que estabelecer as condições gerais para o exercício do direito ao lazer para todos e todas e a legislação é uma esfera 
importante no que tange a administração dos espaços e dos tempos reservados ao lazer para o conjunto dos cidadãos, a gestão dos recursos, instalações e equipamentos que lhe são devidos, o apoio aos organismos da sociedade civil que são promotores de interesses públicos. O primeiro dever do Estado (no que tange o lazer) é de alargar o espectro das possibilidades de acesso às práticas de lazer que podem ser melhor escolhidas pelos cidadãos por causa da gratuidade ou baixos custos.

Uma abordagem política do lazer que se pretende eficaz e operacional em matéria de desenvolvimento humano deve repousar numa planificação não autoritária permanentemente negociada e renegociada periodicamente pela comunicação com os seus beneficiários. O Estado, portanto, não é de nenhuma maneira o único ator legitimado para tratar as orientações e o conteúdo do lazer. Neste caso, o governo deve estabelecer um estado de interação e de ação conjunta entre sociedade civil e sociedade política. Esta maneira de abordar o Estado é oposta à maneira tradicional de Estado autoritário e centralizado. O autor salienta que é necessário que haja um certo ajustamento entre a especificidade do lazer enquanto um comportamento escolhido pelo cidadão e um suporte coletivo/público indispensável para isso. "Da mesma maneira que o Estado participa do combate social contra a ignorância, a doença ou a poluição, ele deve operacionalizar a luta contra a exclusão em lazer, enquanto um componente da qualidade de vida cidadã" (p.168).

O autor apresenta ainda os objetivos fundamentais de um serviço público em lazer: 1. administração dos espaços e meios de vida em uma espécie de contrato social territorial repousando numa repartição equilibrada dos espaços privados e públicos centrados no acesso e participação gerais; 2. enraizamento do lazer público nas necessidades reais e julgadas prioritárias dos indivíduos ou grupos sociais; 3 . tomada de consciência de dados de base subjacentes ao estabelecimento de uma oferta de serviços públicos em lazer: a diversidade e densidade demográfica, a pirâmide de idades, as realidades geográficas e climáticas, o meio rural e urbano, os tipos de emprego, a riqueza, a pobreza e a precariedade, os modos de vida, as relações inter-étnicas, o estado das instituições de serviços em educação, saúde, bem-estar, segurança, a influência dos grupos de interesses, a presença da criminalidade e outros; 4. o uso pertinente dos recursos coletivos; 5 . intensificação do laço social no sentimento de pertença à uma sociocultura em evolução, para a realização de projetos ou de programas coletivos suportados

Movimento, Porto Alegre, v. 10, n. 2, p.147-166, maio/agosto de 2004 
por redes de informação, para a preservação de práticas, de problemas e de conflitos prejudiciais à paz e à coesão social; 6. o suporte da ação comunitária benevolente em favor das pessoas e grupos sociais menos ricos, em situação de risco, deficientes e doentes crônicos, institucionalizados ou não; 7. implantação de instalações e equipamentos públicos, alargando os meios de vida privadas de base e agindo em vista de suscitar um sentimento de pertença e de propriedade coletiva; 8 . reconhecimento do lazer público como instrumento privilegiado de consumo, de expressão e de criação, o que implica: a) priorizar as formas de lazer educativo, b) criar ocasiões de iniciação, aprendizagem e formação contínua ao longo da existência reforçando a capacidade de expressão dos gostos, atitudes, talentos e aspirações da sociedade civil, c) dar suporte à evolução dos modos de vida em relação aos valores hedonistas e estéticos de uma existência de qualidade, d) apoiar a criatividade sob todos os domínios da vida de lazer, e) apoiar as forças e agentes de mudança social e cultural considerados como benéficos e progressistas, f) apoiar a ação das organizações civis quando é útil e desejável enquanto lazer público fundado no direito cívico; 9. desenvolvimento de parcerias múltiplas para satisfazer as necessidades sociais identificadas em colaboração com os atores sociais mais qualificados da sociedade civil, reunidos em redes de serviços complementares e aceitando atuar para o bem público num clima de cooperação e de ajuda mútua.

Bellefleur esclarece que um serviço público de lazer deve: 1. tomar a forma de oferta de serviços gerais ou especializados correspondentes à pluralidade das necessidades à serem satisfeitas levando em conta a variedade das categorias sociais a atender; 2. implicar a participação ativa dos cidadãos na elaboração desta oferta de serviços, nas decisões que ela implica e na sua realização; 3. disponibilizar mecanismos de comunicação e de consulta para ajustar a oferta de serviços às realidades, aos problemas e necessidades existentes; 4 . dar uma atenção especial aos serviços adaptados para cidadãos incapazes de defenderem seus direitos; 5 . realizar a integração dos sistemas de serviços; 6. promover a formação em rede dos atores sociais privados e públicos sobre uma base de afinidades complementares na realização de projetos visando o bem público; 7. ajudar as iniciativas que favoreçam a educação contínua e aprendizagem das diversas formas de lazer; 8. apoiar, sustentar e acompanhar os agentes da mudança social e cultural julgada positiva e benéfica; 9. promover as trocas, a intensificação do laço social e as relações intersocietárias ou interculturais no respeito às diferenças; 10. contribuir para a

Morimento, Porto Alegre, v. 10, n. 2, p.147-166, maio/agosto de 2004 
integração harmoniosa dos imigrantes e dos cidadãos em situação de mobilidade espacial; 11. configurar sua oferta de serviços a partir dos critérios seguintes: a) uma definição das prioridades que respondam corretamente às necessidades e aspirações dos cidadãos, b) uma clarificação dos critérios que definam o interesse e a utilidade públicos, c) a fixação dos parâmetros de uma distribuição justa e equilibrada das fontes coletivas associadas à oferta de serviço, d) o desenvolvimento do uso polivalente dos espaços, equipamentos e instalações de propriedade pública.

Mesmo quando os poderes públicos dispõem de um centro nevrálgico diretamente voltado ao lazer sob forma de ministério, de direção geral ou de serviço particular, este não é suficiente para a tarefa e requer contribuições específicas de outras estruturas do mesmo aparelho público. O lazer é uma questão social que necessita de um tratamento em rede, horizontal e que englobe as diversas instâncias de um mesmo governo. Uma política global é, então, uma necessidade fundamental para garantir a convergência e eficiência do serviço público.

Com um tom otimista que permeia todo o seu livro, Bellefleur encerra suas reflexões afirmando que a oferta de serviços públicos de lazer age como consolidação dos outros serviços que visam a qualidade de vida no seio de uma sociedade. Ela acentua os benefícios dos lazeres já organizados pela sociedade civil generalizando sua acessibilidade, permite a fruição das belas e boas coisas da vida, desenvolve a identidade individual e coletiva, seus modos de vida e reforçam seu potencial de criatividade. Ela favorece ainda a intensificação dos laços sociais, do sentimento de pertença à uma cidadania real.

Bellefleur conclui o livro lembrando a relação entre lazer e qualidade de vida, afirmando que a idéia de lazer é uma das manifestações do caráter ontológico da liberdade humana, como elemento estrutural da existência e como gerador de qualidade de vida. Os elementos da qualidade de vida são: os direitos e liberdades de pensamento, de palavra e de expressão, de associação; o acesso fundamental às condições de vida decente, à educação, saúde, segurança e cultura, à uma cidadania democrática associada à liberdade civil e política. Estes elementos combinados podem constituir a tela de fundo de uma meta-ideologia da qualidade de vida em que se assenta o lazer.

A qualidade de vida "se funda normalmente numa ética do diálogo, do respeito das diferenças culturais e morais, da tolerância 
máxima e da consciência da relatividade das doutrinas ou ideologias particulares que coabitam no seio de uma mesma sociedade, as quais são uma manifestação da pluralidade das 'verdades' humanas. Todos estes elementos podem constituir uma tela de fundo adequada para uma ética do lazer como fenômeno humano resolutamente direcionado para o exercício da liberdade e associado à uma busca constante do hedonismo e da estética" (p.185). A qualidade de vida em lazer é simultaneamente um negócio pessoal coletivo. O lazer encontra facilmente seu lugar nas pulsões de vida polarizadas pela liberdade e o hedonismo utilizados com discernimento, inteligência e julgamento crítico. Ele se apresenta como um germe e um potencial de criatividade inserido num projeto de existência que cada um tem a responsabilidade de cultivar a sua maneira em função dos valores que dão sentido à vida, tanto individual quanto social.

Le loisir contemporain. Essai de philosophie sociale, de Michel Bellefleur, é um livro denso, repleto de informações sobre cultura e lazer. Tem prioritariamente um tom otimista o qual, em algumas passagens, dá a impressão de ser obscurecido, como que por deslize, por uma nuança mais crítica e polêmica. Apesar desta (quase inevitável) contradição que se percebe numa leitura mas atenta, trata-se de um livro que traz contribuições importantes aos estudos multidisciplinares em torno do lazer, sobretudo no que tange as questões sobre políticas públicas de lazer - um tema sobre o qual ainda pouco se publica no Brasil.

The contemporary leisure: an essay of social
philosophy
This book reveals the author's reflexions on the
historical evolution of leisure and contemporary
characteristics of this phenomenon that is seen in a
wide and connected way with culture, life quality,
public services and consumption. Michel Bellefleur
considers leisure as a time-space in which behaviors
based in freedom of choice are possible. For him,
leisure is inserted in a global approach of human
behavior's building of the assembly of which it is a
mediation among others, a mediation capable of
contributing forthe development of both personal and
collective life. Leisure finds its place easily on the
impulses of life polarized in freedom and hedonism
used with discernment, intelligence and critical
judgment. It presents itself as a germen and a creative

Movimento, Porto Alegre, v. 10, n. 2, p.147-166, maio/agosto de 2004 


\begin{abstract}
potential inserted in an existence project that each one has the responsibility to grow in each one's way, according to the values that give sense to life, both individual and social ones.
\end{abstract}

\title{
El ocio contemporáneo: ensaio de filosofia social
}

Resumen: Este libro rebela las reflexiones del autor sobre

a evolución histórica del ocio y las características contemporaneas de este fenómeno que es visto de forma amplia e interligada con a cultura, la cualidad de vida, los servicios públicos y el consumo. Michel Bellefleur considera

el ocio como un tiempo-espacio en que son posibles comportamientos baseados en la libertad de escoger. Para el, el ocio está inscrito en una abordaje global de la estructuración del conjunto del comportamiento humano del cual el es una mediación de entre las otras, una mediación suceptible de contribuir para el desarrollo de la vida personal y colectiva. El ocio encuentra facilmente su lugar en las pulsiones de vida polarizadas por la libertad y el hedonismo utilizados con discernimiento, inteligencia y juzgamento crítico. El se presenta como un germen y un potencial de criatividad inserido en un projecto de existencia que cada un tiene la responsabilidad de cultivar a su manera en función de los valores que dan sentido a la vida, tanto individual como social.

Palabras-chave: Ocio, Consumo, Cualidad de Vida. 